\title{
MAPPING THE SKY
}

\section{PAST HERITAGE AND FUTURE DIRECTIONS}

Edited by

S. DÉBARBAT, J. A. EDDY, H. K. EICHHORN and A. R. UPGREN
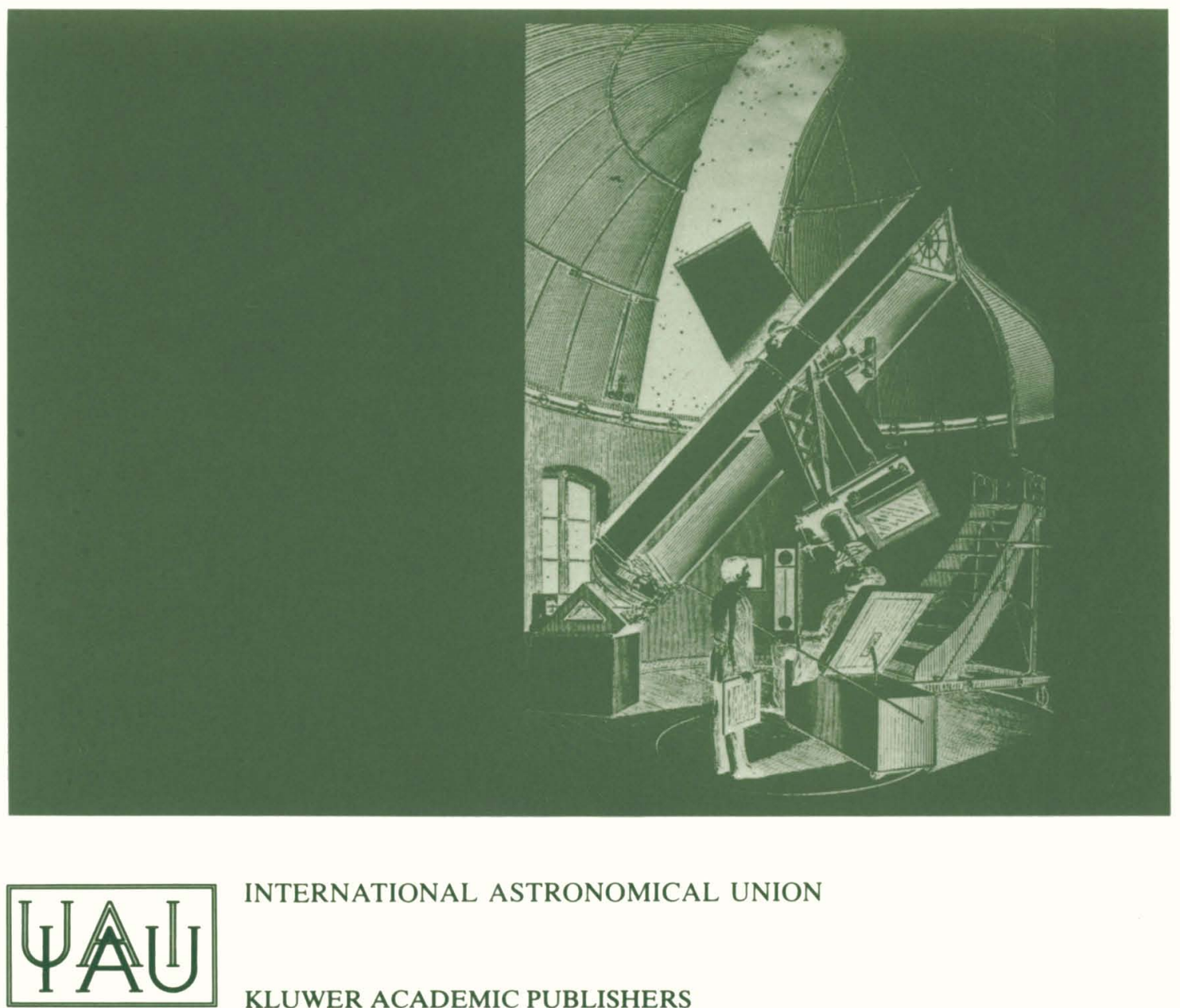

INTERNATIONAL ASTRONOMICAL UNION

KLUWER ACADEMIC PUBLISHERS 
MAPPING THE SKY

PAST HERITAGE AND FUTURE DIRECTIONS 


\title{
MAPPING THE SKY PAST HERITAGE AND FUTURE DIRECTIONS
}

PROCEEDINGS OF THE 133RD SYMPOSIUM OF THE INTERNATIONAL ASTRONOMICAL UNION HELD IN PARIS, FRANCE, JUNE 1-5, 1987

\author{
EDITED BY \\ S. DEBARBAT \\ Observatoire de Paris, Paris, France \\ J. A. EDDY \\ University Cooperation for Atmospheric Research, \\ Boulder, Colorado, U.S.A. \\ H. K. EICHHORN \\ Department of Astronomy, University of Florida, \\ Gainesville, Florida, U.S.A. \\ and \\ A. R. UPGREN \\ Van Vleck Observatory, Wesleyan University, \\ Middletown, Connecticut, U.S.A.
}

\section{KLUWER ACADEMIC PUBLISHERS}

DORDRECHT / BOSTON / LONDON

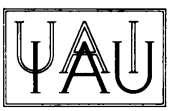


Library of Congress Cataloging in Publication Data

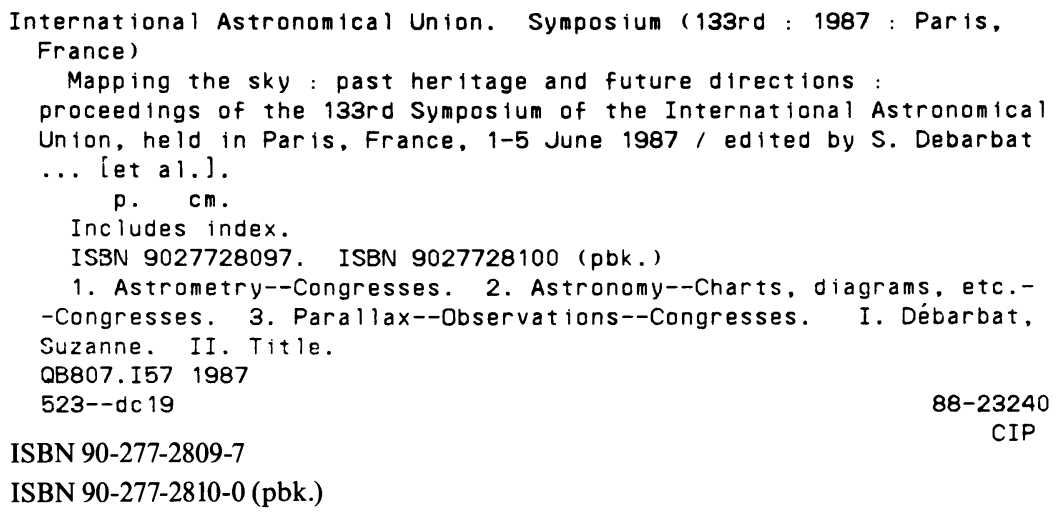

ISBN 90-277-2810-0 (pbk.)

\section{Published on behalf of \\ the International Astronomical Union \\ by}

Kluwer Academic Publishers, P.O. Box 17, 3300 AA Dordrecht, The Netherlands.

Kluwer Academic Publishers incorporates the publishing programmes of

D. Reidel, Martinus Nijhoff, Dr W. Junk and MTP Press.

Sold and distributed in the U.S.A. and Canada

by Kluwer Academic Publishers,

101 Philip Drive, Norwell, MA 02061, U.S.A.

In all other countries, sold and distributed

by Kluwer Academic Publishers Group,

P.O. Box 322, 3300 AH Dordrecht, The Netherlands.

\section{All Rights Reserved \\ (C) 1988 by the International Astronomical Union}

No part of the material protected by this copyright notice may be reproduced or utilized in any form or by any means, electronic or mechanical, including photocopying, recording or by any information storage and retrieval system, without written permission from the publisher.

Printed in The Netherlands 

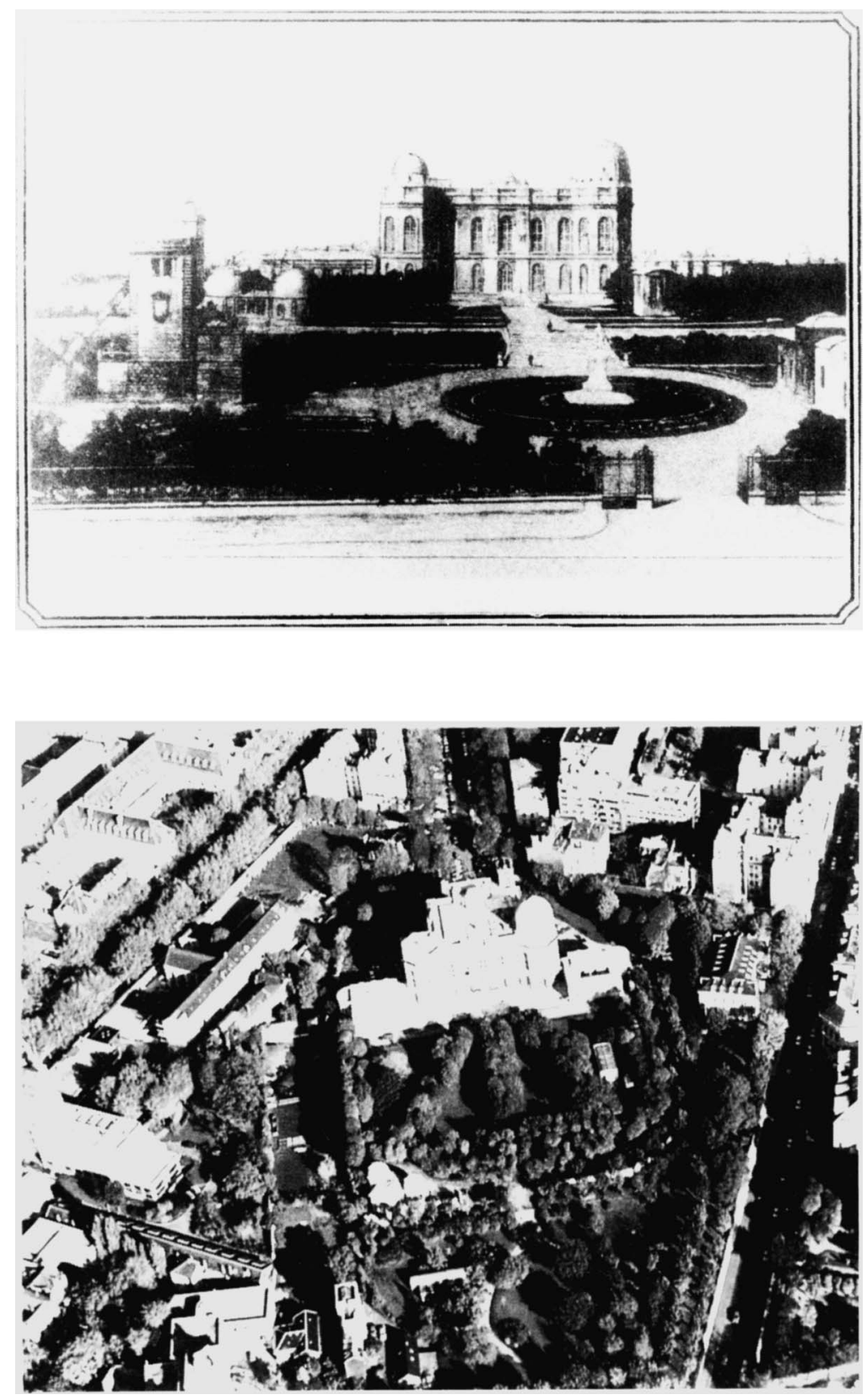

L'Observatoire de Paris en 1887 (sur) et 1987 (sous) Document Bibliothèque de 1'Observatoire de Paris et Interphotothèque de 1a Documentation francaise 
TABLE OF CONTENTS

PREFACE

xiii

LIST OF PARTICIPANTS

Introduction

A. Upgren

Allocution De Bienvenue

Y. Laporte

L'Astronomie Au College De France

J.C. Pecker

Oriental star Maps

F.R. Stephenson

A New Approach To Traditional Chinese Astronomy

$J$. Kistemaker and $Y$. Zhengzong

Naissance Et Developpement De La Carte Du Ciel En France T. Weimer

The Greenwich And Oxford Astrographic Telescopes 1958-1987 D.H.P. Jones

Past, Present, And Future of Photographic Surveys

A. Maury

The Carte Du Ciel - The Australian Connection

G.L. White

Protohistoire De La Machine A. Mesurer Les Cliches

Astronmiques

D. Fauque

T.N. Thiele And The Carte Du Ciel

L.R. Rristensen

The "Carte Du Ciel" Instrument of San Fernando: A Century of Activity

A. Orte

The Third Reduction of Giuseppe Piazzi's Star Catalogue E. Proverbio

Refraction In Tycho Brahe's Small Universe

R.P. Moesgaard 
viii

Fundamental Catalogues

w. Gliese

Documents Pour Une Exposition : La Carte Du Ciel

8. Debarbat

Preserving The Past: Archival Preservation of observatory Publications Via An Optical Disk Project

B.G. Corbin

The First Successful Attempts To Determine stellar

Parallaxes In The Light of The Bessel/Struve Correspondence

W.R. Dick and G. Ruben

Astrometry with The Yale Heliometer, 1882-1910

D. Hoffleit and $w$. van Altena

"Petite histoire" du Congres astrophotographique de 1887

A.M. Motais de Narbonne

Astrographic Catalogues of British Observatories

N.P.J. O'Hora

The Grubb Astrographic Telescopes, 1887-1896

P.A. Wayman

David Gill And Celestial Photography

C.A. Murray

Construction of The system of Positions And Proper Motions In The FK5

H. Schwan

Mapping Coordinate System Irregularities on The Celestial

Sphere

P.D. Hemenway, A.L. Whipple and R.L. Duncombe

Compilation of The Nirs Using The Eichhorn Method

c.8. Cole

Recovery of the Astrographic Catalogue

J. Stock and C. Abad

The Development of The Overlapping-Plate Method

H. Eichhorn

Rigorous Block-Adjustment of The CPC2 Cape Zone

N. Zacharias

Match Criteria for Automatic Alignment of Normal

Astrograph and Schmidt Plate

A. Fresneau 
Status of Photographic Catalogs: Available Material And Future Developments

Ch. de Vegt

The Guide Star Catalog.I. Overview, History And Prospective.

B.M. Lasker, H. Jenkner, and J.L. Russell

The Guide Star Catalog.II. Astrometric And Photometric Algorithms And Precision

J.I. Russell, B.M. Lasker, and H. Jenkner

The Guide Star Catalog. III. Structure And Publication, Status and Plans.

H. Jenkner, J.L. Russell, and B.M. Lasker

A Very Special Catalogue : The Hipparcos Input Catalogue.

c. Turon

Hipparcos : An Example of Astrophysical Uses of Astrometric Data.

A.E. Gomez and F. Crifo

The Tycho Survey of stars Brighter than Eleventh

D. Egret and E. $\mathrm{H} \phi \mathrm{g}$

The Yale Parallax Catalogue

W.F. van Altena and J.T. Lee

The Lick Northern Proper Motion Program

R.B. Hanson

The Tarija-Pulkovo Astrographic Catalogue of The Southern

Sky: First Results And Perspectives

N.F. Bystrov, D.D. Polozhentsev, Kh.I. Potter, I.I. Yagudin, J.A. Zelaya, R.F. Zalles

A Catalog of Reference Stars For New Reductions of The Astrographic Catalog Plates

T.E. Corbin and S.E. Urban

Precise Proper Motions And Positions of Stars From A Combination of Fundamental Catalogues With The Hipparcos Catalogue

R. Wielen

Proper Motions From Carte Du Ciel Plates

w.J. Luyten

Linking Hipparcos To Extragalactic Reference Frame (Task of Input Catalogue Subgroup 2130)

A.N. Argue 
Radio Mapping

E.R. Deul and W.B. Burton

Radio Continuum Surveys of The Sky

R. Wielebinski

The Second Palomar Sky Survey

N. Reid

The Naval Observatory "Short" Plate Being Taken As Part of

The Palomar sky Survey II

D.G. Monet

The Infrared Astronomical Satellite Survey of The Sky

T. Chester

Mapping The Sky - Surveys With Schmidt Telescopes

D.H. Morgan and 8.B. Tritton

The Contribution of The Danjon Astrolabe To The Improvement of The Fundamental Reference System at The Southern

Hemisphere

F. Noel

Mapping The Sky With The Carlsberg Automatic Meridian Circle

L.V. Morrison, L. Helmer and L. Quijano

Astrometry And Data Centers

c. Jaschek

Proper Motion of Determination of The X-Ray Object 3A2254033 Using The Astrographic Catalogue of The San Fernando Zone

$$
\text { A.N. Argue and L. Quijano }
$$

The Compared Efficiency of Centering Algorithms

O. Bienayme, C. Motch, M. Creze and S. Considere

Presentation Technique De L'Astrolabe Photoelectrique Du Cerga

G. Billaud, R. Boche, M. Furia and G. Vigourous

Paris Full Pupil Astrolabe And Danjon's Prism Astrolabe A Statistical Comparison In Terms of Time-Magnitude-Colour Equation

$$
\text { M.I. Bougeard }
$$

Astrometry with Carte Du Ciel Plates

P. Brosche and $M$. Geffert

Vers Un Nouveau Catalogue General Astrolabes

F. Chollet 
The Carte Du Ciel And The Catalogue Photographic Plates of The Bordeaux Observatory

$$
\text { J. Colin and G. Soulie }
$$

Current Status of The Second Cape Photographic Cctalogue Chr. de Vegt, N. Zacharias, M.J. Penston and C.A. Murray

A Prototype Detector For The Astrometric Telescope Facility

G. Gatewood, M.W. Castelaz, E.H. Levy, R.S. McMillan,

K. Nishioka, J.D. Scargle and J.W. stein

The Mama Machine: Proper Motions From Digitization of Centenary Plates

J. Guibert

Solar Motion And Galactic Rotation: Results From The Lick Northern Proper Motion Program

R.B. Hanson

Towards The Definition of A Unified Celestial optical/Radio Reference Frame

J. Hughes, K.J. Johnston, and Ch. de Vegt

The Minnesota Automated Plate Scanner: A New User Facility

R.L. Pennington, R.M. Humphreys and F.D. Ghigo

A Program For A New Reduction of Plates of The Astrographic Catalogue

s. Roser and H. Jahreis

NASA's Astrometric Telescope Facility

J.D. Scargle, K. Nishioka and G. Gatewood

The Tautenburg Part of The Programme studying The Main Meridional Section of The Galaxy

E. schilbach

Optical Positions And Proper Motions of Selected Radio stars

H.M. Schwerdtfeger, R. Hering, H.G. Walter and H. Jahreis

The JPL 1986-3 Extragalactic Reference Frame

O.J. Sovers, C.D. Edwards, C.s. Jacobs, G.E. Lanyi and

R.N. Treuhaft

Proper Motions of 47 TUC And NGC 362 Relative To The Smallo Magellanic Cloud

E. -J Tucholke 
Precision of Parallaxes From Automatic And Manual Measures From New Parallaxes of The Hyades Cluster Region

A.R. Upgren, E.W. Weis, H.-H. Fu and J.T. Lee

The Space Luminosity And Velocity Distribution of Faint stars

W.F. van Altena, J.T. Lee, W.8. TsaY, and P.R. Lu

The Parallax And Proper Motion Program of The Shanghai

Observatory 1.56-M Astrometric Reflector

W. Jia-ji

A Proposal For Mapping The Sky At Deka-Hectometer

Wavelengths: The LFSA

R.W. Weiler, B.R. Dennison, R.J. Johnston, R.s. Simon,

J.H. Spencer, W.C. Erickson, M.L. Kaiser, H.V. Cane,

M.D. Desch, and L.M. Hammarstrom

Mapping The Radio Sky: Compact Radio Quasars From The Parkes 2.7 GHz Survey

D.I. Jauncey, ,G.I. White, B.R. Harvey, M.J. Batty,

A.E. Wright, A. Savage, B.A Peterson, W.L. Peters,

J.E. Reynolds, s. Gulkis, R.A. Preston, D.D. Morabito,

A.K. Tzioumis, J.J. Condon, D.F. Malin, G.D. Nicolson,

A. Nothnagel, A.N. Argue and A. Stolz

Double stars In The Astrographic Catalogue

C.E. Worley

Optical Determination In The Positions of Radio Stars

$x$. Tong-qi, L. Pei-zhen, C. zong-yuan and W. Shu-he

Comparison of The Effect of Various Solar System

Ephemerides on Equator And Equinox Solutions From Six-inch

Transit Circle observations of The Sun

Z.-G. Yao and C. Smith 